University of Windsor

Scholarship at UWindsor

2018

\title{
Comparison of thermal tolerance and standard metabolic rate of two Great Lakes invasive fish species
}

\author{
Ken G. Drouillard \\ David A. Feary Dr \\ The University of Nottingham \\ Xin Sun \\ University of Windsor \\ Jessica A. O'Neil \\ University of Windsor \\ Todd Leadley \\ University of Windsor
}

See next page for additional authors

Follow this and additional works at: https://scholar.uwindsor.ca/glierpub

Part of the Biodiversity Commons, Biology Commons, and the Marine Biology Commons

\section{Recommended Citation}

Drouillard, Ken G.; Feary, David A. Dr; Sun, Xin; O'Neil, Jessica A.; Leadley, Todd; and Johnson, Tim B. Dr. (2018). Comparison of thermal tolerance and standard metabolic rate of two Great Lakes invasive fish species. Comparison of thermal tolerance and standard metabolic rate of two Great Lakes invasive fish species, 6.

https://scholar.uwindsor.ca/glierpub/132

This Article is brought to you for free and open access by the Great Lakes Institute for Environmental Research at Scholarship at UWindsor. It has been accepted for inclusion in Great Lakes Institute for Environmental Research Publications by an authorized administrator of Scholarship at UWindsor. For more information, please contact scholarship@uwindsor.ca. 


\section{Authors}

Ken G. Drouillard, David A. Feary Dr, Xin Sun, Jessica A. O'Neil, Todd Leadley, and Tim B. Johnson Dr 


\title{
Comparison of thermal tolerance and standard metabolic rate of two Great Lakes invasive fish species.
}

\author{
Ken G. Drouillard ${ }^{* 1}$, David A. Feary ${ }^{2}$, Xin Sun ${ }^{1}$, Jessica A. O’Neil ${ }^{1}$, Todd Leadley ${ }^{1}$, \\ Timothy B. Johnson ${ }^{3}$. \\ ${ }^{1}$ Great Lakes Institute for Environmental Research (GLIER), University of Windsor, 401 Sunset Ave., \\ Windsor, ON, Canada, N9B 3P4. Email: kgd@uwindsor.ca. \\ ${ }^{2}$ Fish Ecology Research Group, University of Nottingham, Nottingham, UK, NG7 2RD \\ ${ }^{3}$ Glenora Fisheries Research Station, Ontario Ministry of Natural Resources and Forestry, Picton, ON, \\ Canada, K0K 2T0
}

\begin{abstract}
Round goby (Neogobius melanostomus) and western tubenose goby (Proterorhinus semilunaris) invaded the Laurentian Great Lakes at approximately the same time and area yet have shown substantial differences in their post-invasion success with more rapid establishment and development of much larger abundances of round goby populations throughout the invaded habitat. In this study, we compared differences in physiological performance (thermal tolerance and standard metabolic rate) between round and tubenose goby collected from the Huron-Erie corridor. Tubenose goby were observed to have lower thermal tolerance but exhibited similar standard metabolic rate across environmental temperatures compared to round goby. At temperatures exceeding $31^{\circ} \mathrm{C}$, tubenose goby demonstrated significantly higher mortalities and shorter times to death relative to round goby. The observed differences in thermal tolerance were consistent with differences in the native geographic ranges observed for each species at their southern ranges. The observed differences in physiological performance combined with species differences in other life history traits such body size, reproduction, feeding ecology and habitat affiliation may also explain differences in the invasiveness experienced by these two Great Lakes invasive fish including a greater ability of round gobies to occupy extreme habitats with large water temperature fluctuations.
\end{abstract}

Keywords. Fundamental niche, Respirometry, Thermal tolerance, Aquatic invasive species, Gobiidae

Introduction. Round goby (Neogobius melanostomus) and western tubenose goby (Proterorhinus semilunaris; hereafter referred to as tubenose goby) were first reported in the St. Clair River of the Laurentian Great Lakes in 1990 (Jude et al., 1992). Both species entered the Great Lakes at approximately the same time via ship ballast water, although the subsequent range expansion and degree of invasiveness attributed to each species post-invasion substantially differed. Round goby established populations throughout the entire Great Lakes basin within the first decade of their reported appearance, while confirmation of tubenose goby presence remained restricted to Lake St. Clair and the western basin of Lake Erie for most of its invasion history (Vanderploeg et al., 2002; Kocovsky et al., 2011). Only within the last decade have the tubenose goby been 
reported in eastern Lake Erie and more recently in Lake Superior and Lake Ontario (Kocovsky et al., 2011.; Fuller e. al., 2013). The two species have also exhibited similar differences in their rate of invasive range expansion in other regions such as the Rhine basin, France (Manné et al., 2013).

The two fish species in question exhibit a number of differences in their life history traits which may impact their ability to survive transport vectors (e.g. ship ballast), exploit various habitats and food resources, and/or overcome competition and predator interactions (Shea and Chesson, 2002). Although both species share many commonalities in near shore habitats and substrate affiliations (Jude and DeBoe, 1996; Erös et al., 2005; Dopazo et al., 2008; Didenko, 2013), round goby achieve larger body sizes, show a broader diet niche including utilizing higher trophic level prey items, and have higher diet plasticity in time and space compared to tubenose goby and other goby species (Andraso et al., 2011a,b; Števove and Kováč, 2013; Pettitt-Wade et al., 2015).

Species-specific differences in physiological tolerance and/or metabolic performance attributes may also contribute to differences in each invader's ecological footprint and/or ability to exploit extreme habitats. Differences in physiological tolerance such as acute thermal tolerance correspond to differences in fundamental niche, whereas differences in metabolic performance, e.g. standard metabolic rate, are likely to relate to realized niche differences depending on the nature of resource availability, community composition and interactions of the above factors with abiotic conditions (Beever et al., 2016). Pörtner and Farrell (2008) introduced the oxygen- and capacity-limited thermal tolerance (OCLTT) hypothesis, which states that thermal tolerance, physiological performance and field distribution of ectothermic animals are causally determined by oxygen transport capacity representing a key limitation to their fundamental niche. In contrast, differences in metabolic performance measured as feeding rate versus water temperature interaction between native (Mysis salemaai) and invasive (Hemimysis anomala) mysids of Ireland showed competitive advantages of the invasive species under climate warming scenarios (Penk et al., 2016). The latter implies a greater realized adaptive capacity of the invader (Beever et al., 2016) under disturbance regimes (climate warming) that occur due to differences in metabolic temperature optima between the species of contrast corresponding to a higher invasive impact.

Between the two Great Lakes invasive gobies, round goby has achieved much greater attention with respect to metabolic rate and acute thermal tolerance characterization. Lee and Johnson (2005) characterized the standard metabolic rate (SMR) of round goby across a wide range of temperatures and body sizes, while Cross and Rawding (2009) characterized the critical thermal maximum (CTMax) of this species. No comparable data for tubenose goby are available, and such data are vital to understand whether species-specific differences in physiology have contributed to the species geographic expansion histories or differences in ecological impact. Therefore, the objective of the present study was to determine and compare thermal tolerance and SMR of round and tubenose goby in order to determine if physiological tolerance and/or differences in bioenergetics requirements occur between the two invasive fish species.

Methods. Sample collection and fish husbandry. Fish used for studies were collected by beach seine and minnow trap from the Detroit River during summer and fall of 2012 and 
2014. Both species were collected at the same locations and times. Round goby typically are larger bodied and more abundant than tubenose goby. As such, tubenose goby were retained at the rate of their capture, whereas round goby were size sorted at the time of collection, with only those of comparable size to tubenose goby being retained. Fish were held for 2 months (for use in acute thermal stress trials) or 4 months (for use in standard metabolic rate measurement trials) acclimation periods post field collection in single species communal tanks. Water quality $(\mathrm{pH}$, dissolved oxygen, temperature and conductivity) was monitored weekly. Water temperature was measured using in situ Hobo Tidbit temperature loggers (Hoskin Scientific, Burlington, ON, Canada). Individuals utilized for acute thermal stress trials were maintained in a recirculating system maintained at $22 \pm 0.5^{\circ} \mathrm{C}$, which is the preferred temperature of round goby (Lee and Johnson, 2005). Individuals used in standard metabolic rate measurements were held in a flow-through system subject to normal seasonal temperature changes associated with the Detroit River. During the holding period all fish were initially fed live tubificid worms and weaned onto a commercial fish pellet formulation. All experimental studies were performed following ethical review by the University of Windsor Animal Care Committee.

Acute thermal stress. Experimental trials were conducted in two $50 \mathrm{~L}$ glass aquaria designated for 'control' and 'treatment' animals. Each tank was partitioned into two equal sections by plastic mesh. The control tank received 5 fish per species, while the treatment 10 fish per species. All individuals were fasted for $24 \mathrm{~h}$ prior to trials. Each trial was initiated at $22^{\circ} \mathrm{C}$. The control tank was maintained at $22^{\circ} \mathrm{C}$ throughout the experimental period. Water temperatures in the treatment tank was increased at a constant rate of $2^{\circ} \mathrm{C} \cdot \mathrm{hr}^{-1}$ until the target temperature $\left(31,32,33,34,35^{\circ} \mathrm{C}\right)$ was reached for a the trial. After the target temperature was reached, water temperature was held constant for $12 \mathrm{~h}$ (measured every 10 minutes) until the trial completion.

Pilot observations and previous work on round goby (Cross and Rawding, 2009) indicated that the onset of muscle spasms is indicative of impending death. This endpoint was used as a surrogate measure of death during each 12 hour trial period. Immediately following onset of muscle spasm, individuals were removed and euthanized by overdose of anesthetic agent and the time of death recorded. At trial end the cumulative \%mortality of each species was determined. Acute thermal stress trials were performed sequentially using different sets of fish from the communal tank for each trial. Triplicate trials were performed at each target temperature.

A general linear model (GLM) was applied to test for species $\mathrm{x}$ temperature interactions using the combined data to determine if differences in $\mathrm{LC}_{50}$ between species occurred according to the following model:

$$
\text { Mortality }(\text { Probit })=\ln T+\text { Species }+ \text { Species } x \ln T+\text { Constant }
$$

Where Mortality (Probit) is the probit transformed percent of individuals for a given species succumbing to death after $12 \mathrm{~h}, \ln$ "T" is the natural logarithm of temperature $\left({ }^{\circ} \mathrm{C}\right)$ for the trial and Species was set to a categorical value (round goby $=1$ or western tubenose goby $=0$ ). Values of $0 \%$ and $100 \%$ mortality are undefined under probit transformation and therefore were removed before analysis. Prior to performing the GLM, data normality was tested using Lilliefors Test. After testing the model, the interaction term $($ Species $x \ln T)$ was found to be significant $\left(F_{1,16}=6.673, p<0.05\right)$ 
indicating differences in LC50 between the species. As such, linear regressions were subsequently performed separately for each species and used to extrapolate the $12 \mathrm{~h}$ LC50 and $95 \%$ confidence interval (CI) around the $\mathrm{LC}_{50}$ value.

Standard metabolic rate. Prior to initiating the SMR study, ambient water temperature of holding tanks was $5^{\circ} \mathrm{C}$ and all fish were assumed to have acclimated to cold conditions. Both communal tanks were then switched from flow-through to a recirculation system, with water temperature brought up to $10^{\circ} \mathrm{C}$ over $72 \mathrm{~h}$. Following respiration trials at $10^{\circ} \mathrm{C}$, experimental water temperatures within aquaria were then slowly increased to the next temperature treatment over a $72 \mathrm{~h}$ period $\left(18^{\circ} \mathrm{C}, 23^{\circ} \mathrm{C}, 26^{\circ} \mathrm{C}\right.$, $30^{\circ} \mathrm{C}$ ) and maintained until the next set of measurements were completed.

To measure individual oxygen consumption a single chamber intermittent flow respirometer (Loligo® Systems, Denmark) was used following Leadley et al. (2016). The respirometry chamber had dimensions of $33 \mathrm{~mm}$ diameter x $100 \mathrm{~mm}$ length. A submersible galvanic oxygen probe (MINI-DO, Loligo Systems, Denmark) was used to measure oxygen concentration in the respirometry chamber during measurement periods. AutoResp software provided automated system control and data collection. Each measurement trial used one fish per chamber and lasted for 18 to $27 \mathrm{~h}$. During each trial the system was sequentially looped through two stages: (i) the measuring period, where the chamber was sealed with $\mathrm{O}_{2}$ concentration logged through time, and (ii) the flush period, where oxygenated water was pumped through the chamber until the next measurement period. Measurement/flush periods were set to 300s and 130s, respectively except for the $30^{\circ} \mathrm{C}$ temperature trials where periods were set to $120 \mathrm{~s}$ and 110 s to reduce oxygen sags.

Respirometry trials were conducted under dark conditions using three separate trials on individual fish of each species within each temperature treatment. All individuals were fasted for $24 \mathrm{~h}$ prior to trial initiation. Each individual had its total length $(\mathrm{mm})$, standard length $(\mathrm{mm})$, weight $(\mathrm{g})$ and volume ( $\mathrm{mL}$; by water displacement) measured (under sedation within a solution of MS222), and was then placed within the trial chamber. Individuals from each species were used only once per trial. The exception was the $26^{\circ} \mathrm{C}$ and $30^{\circ} \mathrm{C}$ tubenose goby trials, where, due to limited availability of fish, the same three individuals were used at both temperatures. To control for effects of background oxygen depletion within the respirometer, trials blanks were incorporated by adding a $3.8 \mathrm{~g}$ glass flask stopper as a fish surrogate within the chamber and oxygen measurements taken over the $24 \mathrm{~h}$ period at each experimental temperature. Blank oxygen consumption readings were subtracted from oxygen consumption readings within each temperature treatment.

Respirometry data for round and tubenose goby trials were censored to eliminate the first 4 hours of measurements, where fish were still recovering from anesthesia and handling stress (Leadley et al., 2016). To remove additional artifact measurements during the trial period, SMR data were censored to include only measurements that fell within the $25-75 \%$ quartiles of the distribution of measurements taken during a trial. The mean of the censored data was then used to establish an integrated SMR estimate for each individual. The integrated SMR value for each individual was used as the unit of replication. All SMR data are expressed in units of $\mathrm{mg} \mathrm{O} \cdot \mathrm{g}^{-1} \cdot \mathrm{d}^{-1}$. 
GLM was used to test for species differences in SMR while accounting for body mass, temperature and all interactions according to:

$\ln \mathrm{SMR}=\ln \mathrm{BW}+\ln \mathrm{T}+$ Species $+\ln \mathrm{BW} x$ Species $+\ln \mathrm{BW} \times \mathrm{T}+\ln \mathrm{T} x$ Species $+\ln \mathrm{T} x \ln \mathrm{BW} x$ Species + Constant

Where ' $\mathrm{BW}$ ' is body mass (g). Following initial model fit to the data, it was observed that all interaction terms were non-significant ( $\ln B W x$ Species $F_{1,36}=0.289$, $p>0.5$; ln BW x Temperature $F_{1,36}=0.023, p>0.8 ;$ ln Temperature x Species $F_{1,36}=0.201, p>0.6$; $n$ Temperature $\mathrm{x} \ln \mathrm{BW} x$ Species $\mathrm{F}_{1,36}=0.218, \mathrm{p}>0.6$ ). The adjusted $\mathrm{R}^{2}$ of the model fit was 0.51 and corrected Akaiki Information Criterion (AIC) was 90.8. Given the lack of significance, all interaction terms were removed and the model was re-run to the simplified model:

$\ln \mathrm{SMR}=\ln \mathrm{BW}+\ln \mathrm{T}+$ Species + Constant

The simplified model explained nearly the same degree of variance as the full model $\left(\mathrm{R}^{2}\right.$ $=0.54$ ) and showed an improved AIC of 80.52. As such, the simplified model was retained and used for analysis. For data presentation purposes, SMR values were sizecorrected to a standard $5 \mathrm{~g}$ fish based on the best fit GLM model to the data (Eq 11):

$$
S M R_{S C}=\frac{5^{-0.894}}{\mathrm{BW}^{-0.894}} x S M R
$$

Where $\mathrm{SMR}_{\mathrm{sc}}$ refers to the body size corrected SMR for a $5 \mathrm{~g}$ equivalent sized fish and SMR is the empirically measured SMR in an individual fish. Similarly, SMR values were temperature corrected $\left(\mathrm{SMR}_{\mathrm{tc}}\right)$ to a common water temperature of $21^{\circ} \mathrm{C}$ to illustrate body size relationships according to:

$$
S M R_{t c}=\frac{\ln (1.339 \times 21)}{\ln (1.339 \times T)} \times S M R
$$

Results. Acute thermal stress. The mean \pm standard error (range) body mass of round and tubenose goby was $2.27 \pm 0.06$ (1.63 to $3.07 \mathrm{~g}$ ) and $1.92 \pm 0.06 \mathrm{~g}$ (1.29 to $3.02 \mathrm{~g}$ ), respectively. Despite attempts to size grade fish and use similar size ranges within experiments, tubenose goby were significantly smaller ( $\mathrm{p}<0.001$; Kruskal Wallis) than round goby.

Average temperature induced mortalities were $7 \%$ for round goby and $3 \%$ for tubenose goby at the lowest temperature treatment $\left(30.5^{\circ} \mathrm{C}\right)$ (Figure 1). Mortality increased for both species with increasing water temperature. Average mortality for tubenose goby was $90 \%$ at $33.9^{\circ} \mathrm{C}$ so no trials were conducted for this species at $35.4^{\circ} \mathrm{C}$. At this highest temperature, average mortality was $90 \%$ for round goby. Regression equations of probit transformed mortality versus water temperature were:

Round goby: Probit $(\%$ Mortality $)=0.52 \pm 0.063 \cdot \mathrm{T}-12.4 \pm 2.1 ; \mathrm{R}^{2}=0.84 ; \mathrm{p}<0.001 ; \mathrm{df}=12$;

Tubenose goby: Probit $(\%$ Mortality $)=0.81 \pm 0.069 \cdot \mathrm{T}-21.0 \pm 2.2 ; \mathrm{R}^{2}=0.93 ; \mathrm{p}<0.001$; $\mathrm{df}=10$

Figure 2 presents LT50's as a function of water temperature for each species as described by Eqs. 4 and 5 . 
Based on Eq. 6, the $12 \mathrm{~h} \mathrm{LC} 50(95 \% \mathrm{CI})$ for round goby was $33.4^{\circ} \mathrm{C}(32.0-$ $\left.34.9^{\circ} \mathrm{C}\right)$, while the $12 \mathrm{~h} \mathrm{LC} 50(95 \% \mathrm{CI})$ for the tubenose goby was $32.2^{\circ} \mathrm{C}\left(31.5-32.8^{\circ} \mathrm{C}\right)$. Notably, the $12 \mathrm{~h} \mathrm{LC}_{50}$ determined for round goby in the present study was identical to the CTMax (crtical thermal maximum) of $33.4 \pm 0.3^{\circ} \mathrm{C}$ reported for this species by Cross and Rawding (2009). GLM revealed that $12 \mathrm{~h}$ mortality differed significantly between species $\left(\mathrm{F}_{1,22}=6.56 ; \mathrm{p}<0.05\right.$; ANOVA $)$, with a significant Species $\mathrm{x}$ Temperature interaction $\left(\mathrm{F}_{1,22}=7.69 ; \mathrm{p}<0.05\right.$; ANOVA $)$. Given the different slopes of Eqs 6-7, the two models intersect at $29.7^{\circ} \mathrm{C}$, corresponding to a \% mortality of $<3 \%$ and below the lowest temperature used among trials.

Table 1 provides linear regression fits and LT50 estimates (time against temperature in which $50 \%$ of the population show mortality) for each temperature and species where cumulative mortalities were sufficient to establish significant linear relationships. For round goby, $\mathrm{LT}_{50}$ was computed for temperature trials of 32.6, 33.9 and $35.4^{\circ} \mathrm{C}$ and showed an expected decrease as a function of water temperature, with mortality occurring sooner as temperature increases. For tubenose goby, $\mathrm{LT}_{50}$ was estimated for temperature trials $31.9,32.6$ and $33.9^{\circ} \mathrm{C}$ and also showed a decrease with temperature. Overall both species show a decline in LT $_{50}$ with increasing water temperature and tubenose goby typically exhibit shorter time to death relative to round goby (Fig. 2). At $32.6^{\circ} \mathrm{C}$, where an $\mathrm{LT}_{50}$ was available for both species, the GLM indicated a significant species effect $\left(\mathrm{F}_{1,27}=77.903 ; \mathrm{p}<0.001\right)$ and Species * Time to death interaction $\left(\mathrm{F}_{1,27}=68.15 ; \mathrm{p}<0.001\right)$. For the $33.9^{\circ} \mathrm{C}$ trial there was a nonsignificant interaction term $\left(\mathrm{F}_{1,49}=0.268 ; \mathrm{p}>0.6\right)$. For extrapolation purposes the relationship between $\log \mathrm{LT}_{50}(\mathrm{~h})$ and water temperature $\left(\mathrm{T} ;{ }^{\circ} \mathrm{C}\right)$ is described below and summarized in Figure 2:

Round goby: $\log \left(\mathrm{LT}_{50}\right)=-0.17 \pm 0.03 \cdot \mathrm{T}+6.6 \pm 0.9 ; \mathrm{R}^{2}=0.96 ; \mathrm{p}>0.05 ; \mathrm{df}=3$

Tubenose goby: $\log \left(\mathrm{LT}_{50}\right)=-0.20 \pm 0.02 \cdot \mathrm{T}+7.3 \pm 0.8 ; \mathrm{R}^{2}=0.97 ; \mathrm{p}>0.05 ; \mathrm{df}=2$

Standard metabolic rate. The mean \pm standard error (range) body mass of round and tubenose goby used within SMR trials was $5.93 \pm 0.33 \mathrm{~g}(2.4-10.6 \mathrm{~g})$ and $3.27 \pm$ $0.29 \mathrm{~g}$ ( 1.2 to $5.1 \mathrm{~g})$, respectively. Despite the Species * $\ln \mathrm{BW}$ interaction term not being significant in the general model (Eq 1), there were highly significant differences in body sizes between the species (Kruskal-Wallis; $\mathrm{p}<0.001$ ). The GLM equation fitted to Eq. 3 was as follows:

$\ln \mathrm{SMR}=-1.09 \pm 0.23 \cdot \ln \mathrm{BW}+1.36 \pm 0.25 \cdot \ln \mathrm{T}+0.29 \pm 0.23 \cdot($ species $)-1.35 \pm 0.80$;

$\mathrm{R}^{2}=0.54 ; \mathrm{df}=40$

Where a categorical value of 1 is given for round goby and a value of 0 is provided for tubenose goby. According to the GLM fit, the temperature coefficient and effect of body weight coefficients were highly significant $\left(\ln \mathrm{T} \mathrm{F}_{1,40}=28.82 ; \mathrm{p}<0.001\right.$; $\ln \mathrm{BW} \mathrm{F}_{1,40}=$ $21.92 ; \mathrm{p}<0.001)$. However, the effect of species within the GLM was not significant $\left(\mathrm{F}_{1,40}=1.61 ; \mathrm{p}>0.2\right)$. As such, Eq. 10 was simplified to remove the effect of species yielding a single model to explain SMR for both species: 


$$
\operatorname{Ln} \mathrm{SMR}=-0.89 \pm 0.18 \cdot \ln \mathrm{BW}+1.34 \pm 0.26 \cdot \ln \mathrm{T}-1.40 \pm 0.81 ; \mathrm{R}^{2}=0.54 ; \mathrm{df}=41
$$

The corrected AIC for Eq. 10 was 80.5 compared to 79.7 for Eq. 11. Given the similar $\mathrm{R}^{2}$ value for both equations, smaller AIC of Eq 11 and lack of significance of the species interaction term of Eq. 10, Eq. 11 was considered the more parsimonious model. Species differences in SMR was also tested for individual temperatures categorized into $2^{\circ} \mathrm{C}$ increments using ANOVA. There were no species differences ( $p>0.05$ all tests) in SMR at any tested temperature. Fig 3 presents the model fit of Eq. 11 to the SMR data generated for both species after adjusting for a common body size $(5 \mathrm{~g})$ or common temperature $\left(21^{\circ} \mathrm{C}\right)$ to illustrate body size and temperature SMR relationships.

Discussion. Thermal tolerance in invasive species is most commonly inferred based on their geographic distribution and the thermal maxima apparent within their native range (Braby and Somero, 2006; Miller, 2016). The native range distribution of both round and tubenose goby populations in the Ponto-Caspian region indicate relatively high coexistence along the $45^{\circ} \mathrm{N}$ latitude (Neilsen and Stepien, 2009). Round goby, however, are distributed over greater latitudes at both their northern and southern $\left(50^{\circ} \mathrm{N}\right.$ and $40^{\circ} \mathrm{N}$ latitude) range with corresponding environmental temperatures ranging from -1 to $31^{\circ} \mathrm{C}$ (Ng and Gray, 2011). The results from the present research are consistent with the native southern latitudinal range difference between the species. The present study did not characterize thermal tolerance of the two gobies under cold conditions, however the native range difference between the two species at the northern range would also imply greater fundamental niche for round goby under cold conditions. Indeed, round goby exhibited heightened transcriptional response relative to tubenose goby at both high and low temperature challenges suggestive of expanded fundamental niche at the cold temperature range as well (Welland and Heath, 2017).

Water temperatures in the lethal range $\left(>31^{\circ} \mathrm{C}\right)$ of round and tubenose goby are not likely to be encountered in the open lake or riverine environment of the Huron-Erie corridor or other Great Lakes habitats. However, these temperature extremes may occur on an intermittent basis in shallow/turbid ditches and small creeks which provide connectivity between adjacent aquatic habitats. Differences in life history and resource use behavior may also interact with the above thermal tolerance attributes. For example, round goby utilize a more diverse array of structurally complex benthic habitats (Charlebois et al., 1997; Ray and Corkum, 2001) while tubenose goby show greater preference for still waters (Jude et al., 1992; Kocovsky et al., 2011). Thus a combination of higher temperature tolerance and ability to exploit flowing waters in small channels subject to high temperature fluctuations is consistent with round gobies exploiting extreme habitats and connecting corridors that can better facilitate their local dispersal.

There was no evidence for differences in metabolic performance (standard metabolic rate) over the temperature range of $10^{\circ} \mathrm{C}-30^{\circ} \mathrm{C}$ between the species given that oxygen consumption conformed to the same model predictions in both species (Eq. 9). Compared to Lee and Johnson's (2005) model of round goby respiration, Eq 11 generated similar weight and temperature trajectories but somewhat higher SMR estimates that averaged $17.9 \%$ higher oxygen consumption compared to the earlier published model. These differences may be attributed to different measurement methodologies and 
differences in the body size and temperature range conditions applied across studies. Lee and Johnson (2005) used a manually operated closed respirometer with replicated $(\mathrm{n}=3$ to 10) oxygen consumption measurements taken for each fish after they were sealed in chambers from between 10 minutes to $2 \mathrm{~h}$. The current study used an automated intermittent flow respirometer which collected more numerous measurements (100's of measurements per fish during each trial) over a $24 \mathrm{~h}$ period. However, Lee and Johnson's (2005) study applied measurements over a larger body size range for round goby (1.67 to $64 \mathrm{~g}$ sized fish) and temperature range $\left(3.2\right.$ to $\left.31.3^{\circ} \mathrm{C}\right)$ while round gobies in the present research were limited to fish between 2.4 to $10.6 \mathrm{~g}$ in size and temperatures of 10 to $30.4^{\circ} \mathrm{C}$. However, the main objective of this work was to contrast metabolic rate between the two goby species rather than to reformulate an oxygen consumption model for round goby.

Size differences between round and tubenose goby were significant in both thermal tolerance and SMR measurement trials. In the thermal tolerance trials, the differences in size was relatively small, with mean body weights of $2.27 \mathrm{~g}$ vs $1.92 \mathrm{~g}$ in round and tubenose gobies. These differences were not considered biologically significant and unlikely to interfere with inferences about thermal tolerance between the two species. However, for SMR measurements the differences in body weight between species was larger with average body weights of $5.93 \mathrm{~g}$ vs $3.27 \mathrm{~g}$ for round and tubenose gobies, respectively (See Figure 3). These differences in fish body size ranges could have contributed to the lack of statistical power in the GLM tests used to detect species differences in SMR. Thus, repeating this study over a larger body size range would be useful to determine if the lack of species difference in SMR holds under data with higher statistical resolution.

Some studies have suggested that higher thermal tolerance entails a tradeoff against metabolic performance (Tepolt and Somero, 2014; Magozzi and Calosi, 2015). Thermal acclimation comes with additional metabolic costs related to the synthesis of protein isoforms/heat stress proteins enabling metabolic function over different temperature ranges (Zerebecki and Sorte, 2011) as well as behavioral responses involving feeding and/or avoidance activity (Ford et al., 2004). Indeed, round goby exhibited higher transcriptional response relative to tubenose goby under acute high and low temperature challenges that correspond to the greater acclimation response of round goby (Welland and Heath, 2017). Such differences in transcription response and associated metabolic activity during may not have been great enough to detect under respirometry studies given measurement error of the technique and that the majority of measurements used for metabolic rate determination were taken under non-thermal stress conditions.

Differences in the behavioral responses to chronic thermal stress between the two species are not known. Penk et al. (2016) demonstrated comparable respiration/temperature responses between native (Mysis salemaai) and invasive (Hemimysis anomala) mysids in Ireland. Despite similar metabolic rates between the above species, the invasive mysid exhibited higher food consumption at warmer temperatures that enabled the invader to achieve higher growth potentials under warm conditions (Penk et al., 2016). Lee and Johnson (2005) characterized maximum food consumption rates of round goby and demonstrated a peak in food consumption at $23^{\circ} \mathrm{C}$ and rapidly decreasing consumption after $26^{\circ} \mathrm{C}$ with cessation of feeding at $30^{\circ} \mathrm{C}$. This 
implies optimal growth at $23^{\circ} \mathrm{C}$ and potentially weight loss at temperatures higher than $26^{\circ} \mathrm{C}$. The food consumption/temperature relationship for tubenose goby is not known but would be useful to determine in order to evaluate if energy assimilation potentials differ between the two species at higher temperatures.

Beyond thermal tolerance and potential thermal behavior differences, there are other life history traits that are known to differ between round and tubenose goby which may contribute to differences in their North American dispersal, population sizes and ecological impacts. Tubenose goby are smaller at the first age of reproduction (Corkum et al., 1998; Vanderploeg et al., 2002; Jude et al., 1992) and spawn only once per season whereas larger round goby females will span more than once per season (Corkum et al 1998; MacInnis and Corkum, 2000; Meunier et al., 2009). Round gobies also achieve higher overall body sizes (Kocovsky et al., 2011), exhibit more aggressive behaviors (Groen et al., 2012) and have greater diet plasticity (Pettitt-Wade et al., 2015) compared to tubenose goby. Indeed, the pre-establishment of Dreissenid mussels in the Great Lakes prior to their invasion, coupled with ability of round goby, but not tubenose goby, to exploit this abundant food resource has been noted as a strong contributor to the round goby's establishment success (DeVanna et al., 2011). Finally, round goby have a tendency to drift over a longer number of days during their larval stages compared to tubenose goby which has been hypothesized to both increase their probability of incorporation into ship ballast waters as well as contribute to heightened dispersal in their invasive habitat post establishment (Hensler and Jude, 2007; Janáč et al., 2013).

Conclusion. The standard metabolic rate and acute thermal tolerance of round goby and western tubenose goby was determined in order to contrast metabolic performance and fundamental niche in two Great Lakes aquatic invasive fish species. Both species exhibited similarities in standard metabolic rate over the environmental temperature range of $18-30^{\circ} \mathrm{C}$. However, round gobies exhibited significantly higher thermal tolerance to high temperature stress compared to tubenose. This provides support for differences in fundamental niche between the two species that is consistent with differences in their native geographic range distribution.

Acknowledgements/ The authors would like to thank Dr. L. Corkum for providing suggestions and providing locations for collecting tubenose gobies. This research was supported by an Natural Sciences and Engineering Research Council (NSERC, Canada) Network Grant: Canada Aquatic Invasive Species Network II. Additional support was provided by an Ontario Graduate Scholarship to J.A. O'Neil.

\section{References}

Andraso, G.M., Granger, M.T., Adamczyk, J., 2011a. Size-selective predation by round gobies (Neogobius melanstomus) on dreissenid mussels in the field. J. Great Lakes Res. 37:298-304.

Andraso, G., Cowles, J., Colt, R., Patel, J., Campbell, M., 2011b. Ontogenetic changes in paharyngeal morphology correlate with a diet shift from arthropods to dreissenid mussels in round gobies (Neogobius melanostomus). J. Great Lakes Res. 37:738743. 
Beever, E.A., O'Leary, J., Mengelt, C., West, J.M., Julius, S., Green, N., Magness, D., Petes, L., Stein, B., Nicotra, A.B., Hellmann, J.J., Robertson, A.L., Staudinger, M.D., Rosenberg, A.A., Babij, E., Brennan, J., Schuurman, G.W., Hofmann, G.E., 2016. Improving conservation outcomes with a new paradigm for understanding species fundamental and realized adaptive capacity. Cons. Lett. 9, 131-137.

Braby, C.E., Somero, G.N., 2006. Following the heart: temperature and salinity effects on heart rate in native and invasive species of blue mussels (Genus Mytilus). J. Exp. Biol. 209, 2554-2566.

Charlebois, P.M., Marsden, J.E., Goettel, R.G., Wolfe, R.K., Jude, D.J., Rudnicka, S., 1997. The round goby, Neogobius melanostomus (Pallas), a review of European and North American literature. Illinois- Indiana Sea Grant Program and Illinois Natural History Survey. INHS Special Publication No. 20.

Corkum, L.D., MacInnis, A.J., Wickett, R.G., 1998. Reproductive habits of round gobies. J. Great Lakes Res. 3, 13-20.

Cross, E.E., Rawding, R.S., 2009. Acute thermal tolerance in the round goby, Apollonia melanostoma (Neogobius melanostomus). J. Therm. Biol. 34, 85-92.

DeVanna, K.M., Bodamer, B.L., Wellington, C.G., Hammer, E., Mayer, C.M., Bossenbroek, J.M., 2011. An alternative hypothesis to invasional meltdown in the Laurentian Great Lakes region: general facilitation by Dreissena. J. Great Lakes Res. 37, 632-641.

Didenko, A.V., 2013. Gobiids of the Dniprodzerzhynsk reservoir (Dnieper River, Ukraine): Distribution and habitat preferences. Acta. Ichtyol. Pisc. 43, 257-266.

Dopazo, S.N., Corkum, L.D., Mandrak, N.E., 2008. Fish assemblages and environmental variables associated with gobiids in nearshore areas of the lower Great Lakes. J. Great Lakes Res. 34, 450-460.

Erös, T., Sevcsik, A., Tóth, B., 2005. Abundance and night-time habitat use patterns of Ponto-Caspian gobiid species (Pisces, Gobiidae) in the littoral zone of the River Danube, Hungary. J. Appl. Ichthy. 21, 350-357.

Ford, J.M., Tibbetts, I.R., Carseldin, L., 2004. Ventilation rate and behavioural responses of two species of intertidal goby (Pisces: Gobiidae) at extremes of environmental temperature. Hydrobiologia 528, 63-73.

Fuller, P., Nico, L., Maynard, E., Larson, J., Fusaro, A., 2013. Proterorhinus semilunaris. Retrieved June 27, 2013 from USGS Nonindigenous Aquatic Species Database: http://nas.er.usgs.gov/queries/FactSheet.aspx?speciesID=714.

Groen, M., Sopinka, N.M., Marentette, J.R., Reddon, A.R., Brownscombe, J.W., Fox, M.G., Marsh-Roll, S.E., Balshine, S., 2012. Is there a role for aggression in round goby invasion fronts? Behaviour 149, 685-703.

Hensler, S.R., Jude, D.J., 2007. Diel vertical migration of round goby larvae in the Great Lakes. J. Great Lakes Res. 33, 295-302.

Janáč, M., Šlapanský, L., Valová, Z., Juajda, P., 2013. Downstream drift of round goby (Neogobius melanostomus) and tubenose goby (Proterorhinus semilunaris) in their non-native area. Ecol. Freshwat. Fish 22:430-438.

Jude, D.J., DeBoe, S.F., 1996. Possible impacts of gobies and other introduced species on habitat restoration efforts. Can. J. Fish. Aquat. Sci. 53 (Suppl. 1), 136-141. 
Jude, D.J., Reider, R.H., Smith, G.R., 1992. Establishment of Gobiidae in the Greta Lakes Basin. Can. J. Fish. Aquat. Sci. 49, 416-421.

Kocovsky, P.M., Tallman, J.A., Jude, D.J., Murphy, D.M., Brown, J.E. Stepien, C.A., 2011. Expansion of Tubenose gobies (Proterorhinus semilunaris) into Western Lake Erie and potential effects on native species. Biol. Invasions 13, 2775-2784.

Leadley, T.A., McLeod, A.M., Johnson, T.B., Heath, D., Drouillard, K.G., 2016. Uncovering adaptive versus acclimatized alterations in standard metabolic rate in brown bullhead (Ameirus nebulosus). Can. J. Fish. Aquat. Sci. 76, 973-981.

Lee, V.A., Johnson, T.B., 2005. Development of a bioenergetics model for the round goby (Neogobius melanostomus). J. Great Lakes Res. 31, 125-134.

MacInnis, A.J., Corkum, L.D., 2000. Fecundity and reproductive season of the round goby (Neogobius melanostomus) in the upper Detroit River. T. Am. Fish. Soc. 129, 136-144.

Magozzi, S., Calosi, P., 2015. Integrating metabolic performance, thermal tolerance, and plasticity enables for more accurate predictions on species vulnerability to acute and chronic effects of global warming. Global Change Biol. 21, 181-194.

Manné, S., Poulet, N., Dembski, S., 2013. Colonisation of the Rhine basin by non-native gobiids: An update of the situation in France. Knowl. Manag. Aquat. Ecosyst. 411, 02.

Meunier. B,, Yavno, S., Ahmed, S., Corkum, L.D., 2009. First documentation of spawning and nest guarding in the laboratory by the invasive fish, the round goby (Neogobius melanostomus). J. Great Lakes Res. 35, 608-612.

Miller, K.B., 2016. Forecasting at the edge of the niche: Didemnum vexillum in Southeast Alaska. Mar. Biol. 163,1-12.

Mombaerts, M., Verreycken, H., Volckaert, F.A.M., Huyse, T., 2014. The invasive round goby Neogobius melanstomus and tubenose goby Proterorhinus semilunaris: two introduction routes in Belgium. Aquat. Invas. 9, 305-314.

Neilson, M.E., Stepien, C.A., 2009. Evolution and phylogeography of the tubenose goby genus Proterorhinus (Gobiidae: Teleostei): evidence for new cryptic species. Biol. J. Linn. Soc. 96, 664-684.

$\mathrm{Ng}$, C.A., Gray, K.A., 2011. Forecasting the effects of global change scenarios on bioaccumulation patterns in Great Lakes species. Global Change Biol. 17, 720-733.

Penk, M.R., Jeschke, J.M., Minchin, D., Donohue, I., 2016. Warming can enhance invasive success through asymmetries in energetic performance. J. Anim. Ecol. 85, 419-426.

Pettitt-Wade, H., Wellband, K.W., Heath, D.D., Fisk, A.T., 2015. Niche plasticity in invasive fishes in the Great Lakes. Biol. Invas. 17, 2565-2580.

Pörtner, H.O., Farrell, A.P., 2008. Physiology and climate change. Science 322, 690-692.

Ray, W.J., Corkum, L.D., 2001. Habitat and site affinity of the round goby. J. Great Lakes Res. 27, 329-334.

Schneider, K.R., 2008. Heat stress in the interdial: comparing survival and growth of an invasive and native mussel under a variety of thermal conditions. Biol. Bull. 215, 253-264.

Shea, K., Chesson, P., 2002. Community ecology theory as a framework for biological invasions. TREE. 17, 170-176. 
Sorte, C.J.B., Williams, S.L., Carlton, J.T., 2010a. Marine range shifts and species introductions: comparative spread rates and community impacts. Glob. Ecol. Biogeogr. 19, 303-316.

Sorte, C.J.B., Williams, S.L., Zarebecki, R.A., 2010b. Ocean warming increases threat of invasive species in a marine fouling community. Ecology 91, 2198-2204.

Stepien, C.A., Brown, J.E., Neilson, M.E., Tumeo, M.A., 2005. Genetic diversity of invasive species in the Great Lakes versus their Eurasian source populations: Insights for risk analysis. Risk Anal. 25, 1043-1060.

Števove, B., Kováč, V., 2013. Do invasive bighead goby Neogobius kessleri and round goby N. melanostomus (Teleostei, Gobiidae) compete for food? Knowl. Managet. Aquatic Ecosyst. 410: 08

Tepolt, C.K., Somero, G.N., 2014. Master of all trades: thermal acclimation and adaptation of cardiac function in a broadly distributed marine invasive species, the European green crab, Carcinus maenas. J. Exp. Biol. 217, 1129-1138.

Vanderploeg, H.A., Naleopa, T.F., Jude, D.J., Mills, E.L., Holeck, K.T., Liebig, J.R., Grigorovich, I.A., Ojaveer, H., 2002. Dispersal and emerging ecological impacts of Ponto-Caspian species in the Laurentian Great Lakes. Can. J. Fish. Aquat. Sci. 59, 1209-1228.

Welland, K.W., Heath, D.D., 2017. Plasticity in gene transcription explains the differential performance of two invasive fish species. Evolut. Appl. 10, 563-576.

Zarebecki, R.A., Sorte, C.J.B., 2011. Temperature tolerance and stress proteins as mechanisms of invasive species success. PLoS ONE 6, e14806. 
Table 1. Linear regression coefficients and constants between cumulative mortality and time for round goby and tubenose goby at different water temperatures. LT50 is the regression extrapolated time to $50 \%$ lethality (minutes) and associated $95 \%$ confidence interval.

\begin{tabular}{|llllllll|}
\hline Species & $\begin{array}{l}\text { Temp } \\
\left({ }^{\circ} \mathrm{C}\right)\end{array}$ & $\begin{array}{l}\text { Slope } \\
\pm \mathrm{SE}\end{array}$ & $\begin{array}{l}\text { Constant } \\
\pm \mathrm{SE}\end{array}$ & $\mathrm{R}^{2}$ & $\mathrm{P}$ & $\mathrm{df}$ & $\begin{array}{l}\mathrm{LT}_{50} \\
(95 \mathrm{CI})\end{array}$ \\
\hline $\mathrm{RG}$ & 32.6 & $0.12 \pm 0.02$ & $3.4 \pm 0.2$ & 0.66 & $<0.01$ & 8 & $13.9(0-32.9)$ \\
$\mathrm{RG}$ & 33.9 & $0.15 \pm 0.02$ & $3.5 \pm 0.2$ & 0.76 & $<0.001$ & 16 & $9.8(5.4-14.2)$ \\
$\mathrm{RG}$ & 35.4 & $0.19 \pm 0.02$ & $4.1 \pm 0.1$ & 0.78 & $<0.001$ & 25 & $4.8(0.8-8.8)$ \\
\hline $\mathrm{TG}$ & 31.9 & $0.19 \pm 0.04$ & $3.5 \pm 0.2$ & 0.70 & $<0.001$ & 9 & $8.0(0-18.0)$ \\
TG & 32.6 & $0.21 \pm 0.03$ & $3.9 \pm 0.1$ & 0.74 & $<0.001$ & 19 & $5.2(2.0-8.3)$ \\
$\mathrm{TG}$ & 33.9 & $0.16 \pm 0.05$ & $4.5 \pm 0.2$ & 0.28 & $<0.01$ & 25 & $3.1(0-11.8)$ \\
\hline
\end{tabular}

Fitted regression: Cumulative Mortality $=$ Slope $*$ Time + Constant. 


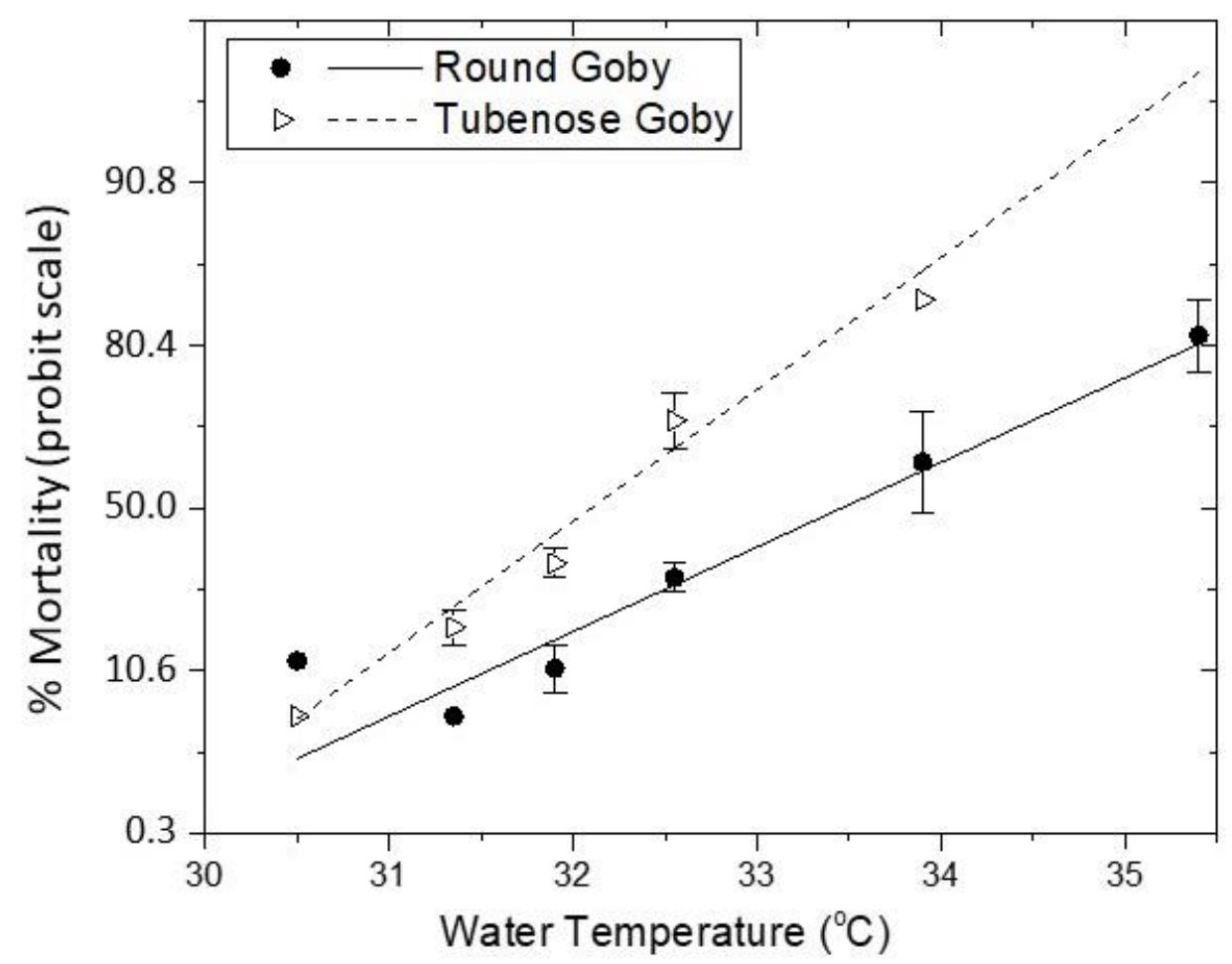

Fig. 1. Mean \pm standard error cumulative mortality after $12 \mathrm{~h}$ exposure to target temperature in round and tubenose goby. 
Drouillard et al. 2018. Journal of Great Lakes Research, Accepted Feb 28, 2018

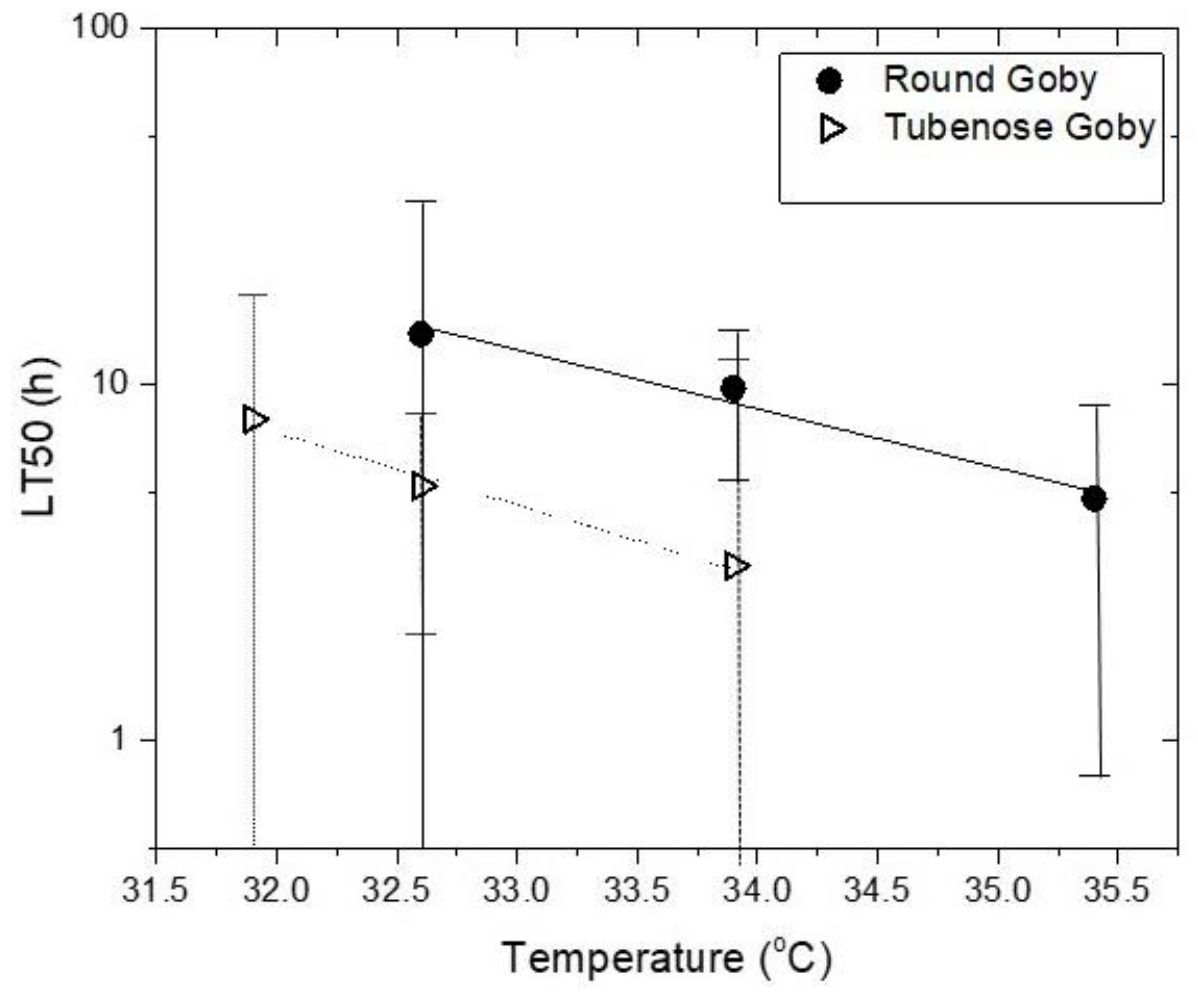

Fig. 2. Mean $\pm 95 \%$ confidence interval of LT50 (h) as a function of water temperature in round and tubenose goby 

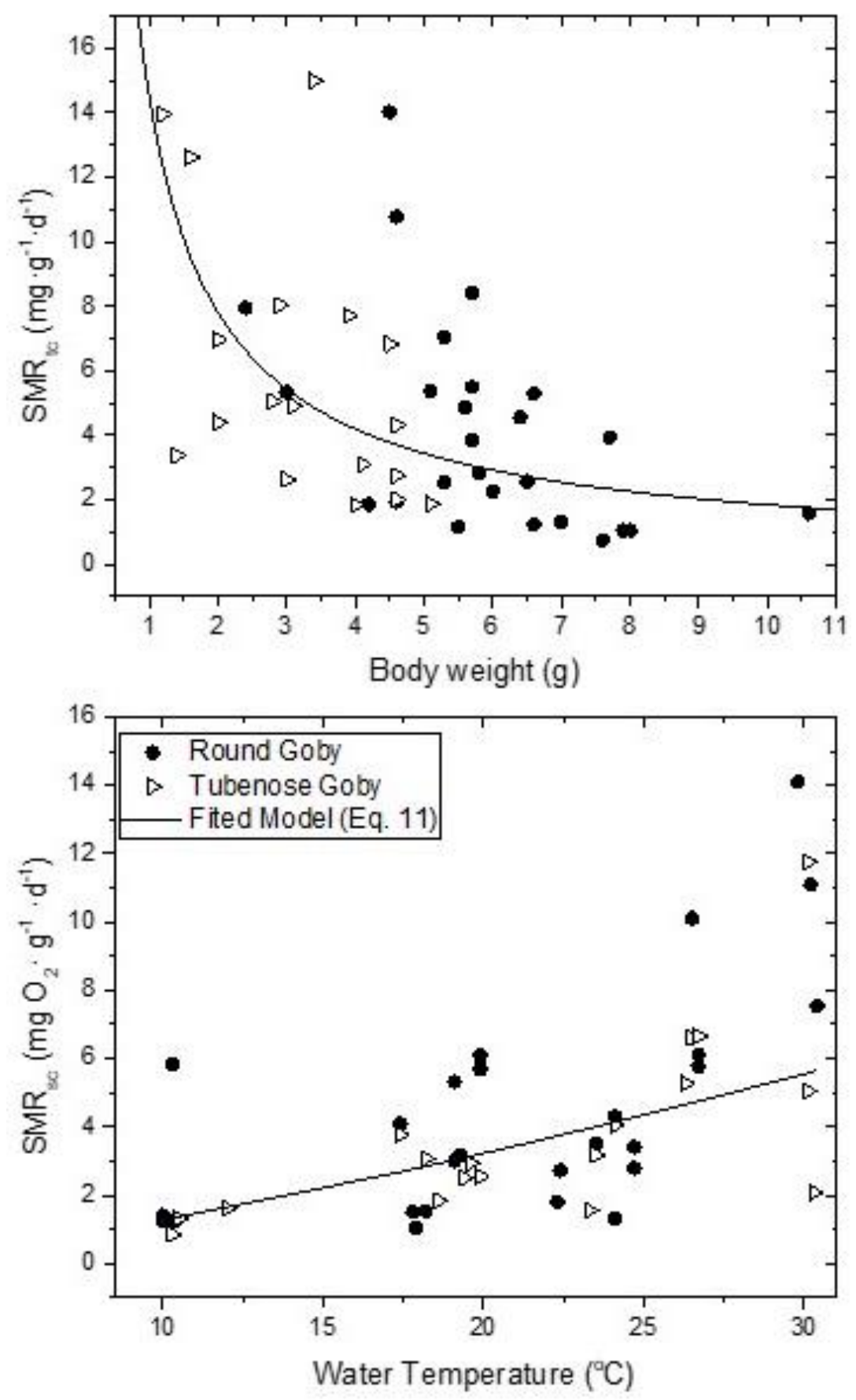

Fig 3. Temperature corrected standard metabolic rate (SMRtc) of round and tubenose goby (Top) and size corrected standard metabolic rate (SMRss) of round and tubenose goby (Bottom) determined in respirometry study. 
Drouillard et al. 2018. Journal of Great Lakes Research, Accepted Feb 28, 2018

\section{Data Statement.}

Raw data used within manuscript are published as a data statement in spreadsheet format accompanying the publication in J. Great Lakes Research. Requests for the data statement can be further relayed to kgd@ uwindsor.ca. 